\title{
Locating Continuing Professional Development within a Proposed Complex Dynamic Systems Model for Today's English Language Teaching Profession
}

\author{
Dianne Tyers $\mathcal{E}$ Judy Sillito
}

For novice and expert English language teaching professionals alike, it is important to understand the dynamic complexity of the context in which we work to intentionally and strategically forge a relevant and personally meaningful, continuing professional development path. English language teaching has long outgrown a "one-size-fits-all" continuing professional development model. Rather, the context in which we teach influences the knowledge and skills we need to develop and maintain as we move through our careers. This, in turn, drives the strategic choices we make for our continuing professional development. However, what does context in English language teaching actually mean, and how do we unpack its elements to locate ourselves within it? Using a proposed model of nested complex dynamic systems, we can first locate ourselves within a broad socioeconomic, complex dynamic system created by the ongoing interaction of a society's economy, politics, history, geography, technology, culture, language, and education. We can then locate ourselves within multiple complex dynamic systems in the professional, program, and classroom contexts that give shape to and, at times, constrain our agency. Finally, we can consider ourselves, English language teachers, as complex dynamic systems. Each of us is the unique creation of our interacting education and training, professional experience, and self. This complex dynamic systems model can be used to guide teachers, administrators, and funders to intentionally and strategically select, design, or support continuing professional development, leading to teachers' building knowledge and practice for ongoing success in a rapidly evolving profession.

Qu'il s'agisse de débutants ou de professeurs expérimentés, il est important que les professionnels de l'enseignement de l'anglais comprennent la complexité dynamique du contexte dans lequel nous travaillons afin de pouvoir ouvrir intentionnellement et stratégiquement la voie à un mode de perfectionnement professionnel continu qui soit à la fois pertinent et significatif sur le plan personnel. Il y a longtemps que l'enseignement de l'anglais ne tient plus dans un modèle unique de perfectionnement professionnel continu. Il faut plutôt reconnaître que le contexte dans lequel nous enseignons influe sur les connaissances et les compétences que nous devons développer et entretenir au fil de notre carrière, ce qui a pour effet d'orienter les choix stratégiques que nous effectuons pour notre perfectionnement professionnel continu. Mais que signifie réellement le contexte de l'enseignement 
de l'anglais, et comment en dégageons-nous les éléments afin de nous y inscrire personnellement? À l'aide d'un modèle suggéré de systèmes dynamiques complexes imbriqués, nous pouvons commencer par nous situer dans un vaste système socioéconomique complexe créé par l'interaction continue de l'économie, de la politique, de l'histoire, de la géographie, de la technologie, de la culture, de la langue, et de l'éducation. Nous pouvons ensuite nous situer à l'intérieur de multiples systèmes dynamiques complexes dans les contextes de la profession, du programme, et de la salle de classe qui donnent forme à notre agentivité et parfois la limitent. Enfin, nous pouvons nous considérer nous-mêmes, en tant que professeurs d'anglais, comme des systèmes dynamiques complexes. Nous sommes toutes et tous le produit unique d'une interaction entre notre éducation et notre formation, notre expérience professionnelle et notre identité. Ce modèle de système dynamique complexe peut être utilisé pour amener les enseignants, les administrateurs, et les bailleurs de fonds à sélectionner, concevoir et appuyer intentionnellement et stratégiquement une forme de perfectionnement professionnel continu susceptible d'amener les enseignantes et les enseignants à accumuler des connaissances et des pratiques qui assureront leur succès dans une profession en évolution rapide.

KEYWORDS: continuing professional development, complexity, model, English language teaching, context

\section{Introduction}

The terms complex and dynamic are frequently and rightly used to describe many aspects of English language teaching (ELT) and learning-from the language, to the learners, to the teaching and learning processes, to the classroom (Larsen-Freeman, 1997; De Bot, Lowie, \& Verspoor, 2007; Van Geert, 2008; and Verspoor, de Bot, \& Lowie, 2011). That many, if not all, components of the ELT profession are both complex and dynamic is a stance accepted by academics and practitioners alike. What is absent in the conversation, however, is a practical discussion of how ELT professionals are to analyze, understand, and then navigate this ever-changing complexity as they launch, build, and live out their careers. How are they to make effective and rewarding continuing professional development (CPD) choices or stay relevant, engaged, and motivated amid this dynamic complexity?

An understanding of the importance of context is a good starting point. CPD does not take place in a vacuum; it is situated in a context-a specific space existing at a specific point in time (Young, DePalma, \& Garrett, 2002; Stelma, Fay, \& Zhou, 2013). This distinctive context results from the ongoing interaction of multiple elements and, as such, can be described as one or more complex dynamic systems (CDS). An effective way to understand the 
concept of a CDS is to break it into its component words. A system is a group of elements that together create a unified whole. A complex system is one in which the relationships among the components of the system are mutually influencing, unpredictable, and changeable. A dynamic system is a complex system characterized by constant or varying change over time. Putting these together, a complex dynamic system is one in which the system components are mutually influencing, unpredictable, and changeable, and in which the nature of component interactions and corresponding outcomes changes over time in a non-linear manner (Larsen-Freeman, 1997; De Bot et al., 2007; Larsen-Freeman \& Cameron, 2008; Dörnyei, 2014; Mercer, 2016).

There are additional conceptual layers to CDSs, particularly related to change. For example, the change that CDSs undergo can be small, slow, and gradual or large, rapid, and sudden or any combination of these descriptors. Furthermore, CDSs, despite being continually in a state of change, are not necessarily chaotic. Rather, the systems self-organize into dynamic stability, constantly finding balance among all interacting and evolving factors within their boundaries. In trying to achieve and maintain this dynamic stability, CDSs may gravitate toward select patterns of balance called attractor states. Attractor states are essentially the CDS's preferred states of being, regardless of the factors at play, states where only the most intense force will elicit change. This stands in direct contrast with repellor states, where even the slightest force will initiate change. These fluctuations in and out of stable states within and across CDSs are the triggers of new development and evince a system that is dynamically active in its complexity. These additional conceptual layers deepen our understanding of the nature of change within CDSs and provide additional insight into our ELT contexts (Dörnyei, 2014; Mercer, 2016; Kostoulas, Stelma, Mercer, Cameron \& Dawson, 2017).

Viewing the context in which CPD takes place as one or more CDSs is important because it allows us to understand that our CPD needs are equally complex and dynamic. There is no single, simple CPD need; rather, there are many interwoven, complicated needs. Understanding the dynamic characteristic of our context is also important because it enables us to understand that, as ELT professionals, we cannot remain stagnant. We have to continually learn, evolve, and change direction to stay effective and relevant in our dynamic context.

There are many theories of CDSs, each of which emphasizes different aspects of a system, from the nature of the interactions, to the unpredictability, to the non-linearity, to the resulting outcomes. There are also different growing bodies of research on the application of a CDS lens to deepen our understanding of ELT (Hensley, 2010; Dörnyei, 2014; Mercer, 2016). In looking at CPD through a CDS lens here, however, we do not adhere to any one specific CDS theory or seek to apply CDS methodologically. Rather, we use the CDS lens to shed light on the importance of context to the CPD choices available to ELT professionals. Our model is intended as a practical, analyti- 
cal tool with which professionals can gather information about their contexts, analyze the information, and use it to craft intentional and strategic professional development pathways.

A greater understanding of our context helps us locate ourselves within the dynamic complexity of the ELT sector, the first step in planning our CPD. A starting point to this discussion is to consider the multiple CDSs at play in our daily work as ELT professionals and to understand how they intersect and influence each other and change over time. Possible professional development choices then emerge to help us strategically forge a personally meaningful and rewarding CPD pathway.

In this article, we first present a proposed CDS model for the ELT sector, describe its components, and (most important) suggest how professionals can locate themselves within it. We then discuss the implications of the model in the practical decisions that teachers, administrators, and funders make with respect to CPD.

\section{A Complex Dynamic System Model for English Language Teaching and Continuing Professional Development}

The need for CPD in the ELT profession is no longer up for debate. The exponential growth in the profession, the constant changes in programming, technology, and resources, and the infinite variety of students and their corresponding learning needs, all point to emerging gaps in professional knowledge and skills that have to be bridged on an ongoing basis. It is impossible for individuals to know everything there is to know and do everything that can be done in the profession. As professionals, then, we have to purposefully develop the knowledge and skills relevant to our contexts and our personal and professional goals within those contexts. Using a CDS model as the starting point, we can build individually relevant CPD plans for the knowledge and skills we will learn and the channels through which we will learn them.

As illustrated in Figure 1, our proposed model identifies five CDSs whose interactions create the overall context of English language teachers: the Socioeconomic CDS, the Profession CDS, the Program CDS, the Class CDS, and the Individual CDS. In Figure 1, the arrow represents the dynamic element of the model, the passage of time.

These CDSs are not hierarchical, however, and they are not siloed; they are equal, intersectional, and mutually influencing. In Figure 1, this intersectionality and mutual influencing is represented by shaded rather than solid lines. That said, CDSs vary in size, from the infinitely small to the infinitely large. Smaller CDSs can be what are called nested complex dynamic systems, in that they exist within or are nested within larger systems (Hensley, 2010; Dörnyei, 2016; Mercer, 2016). For example, every Program CDS is nested 
within the larger Profession CDS, and every Class CDS is nested within a larger Program CDS.

In addition, some CDSs partially overlap other CDSs. For example, the Profession CDS, while part of the Socioeconomic CDS relative to the location where the ELT professional is situated, also expands beyond that one Socioeconomic CDS to literally span the globe. Given that English is taught internationally, the profession likewise exists internationally. The Profession CDS, thus, exists at multiple and increasingly larger levels, from local, to regional, to national, to international.

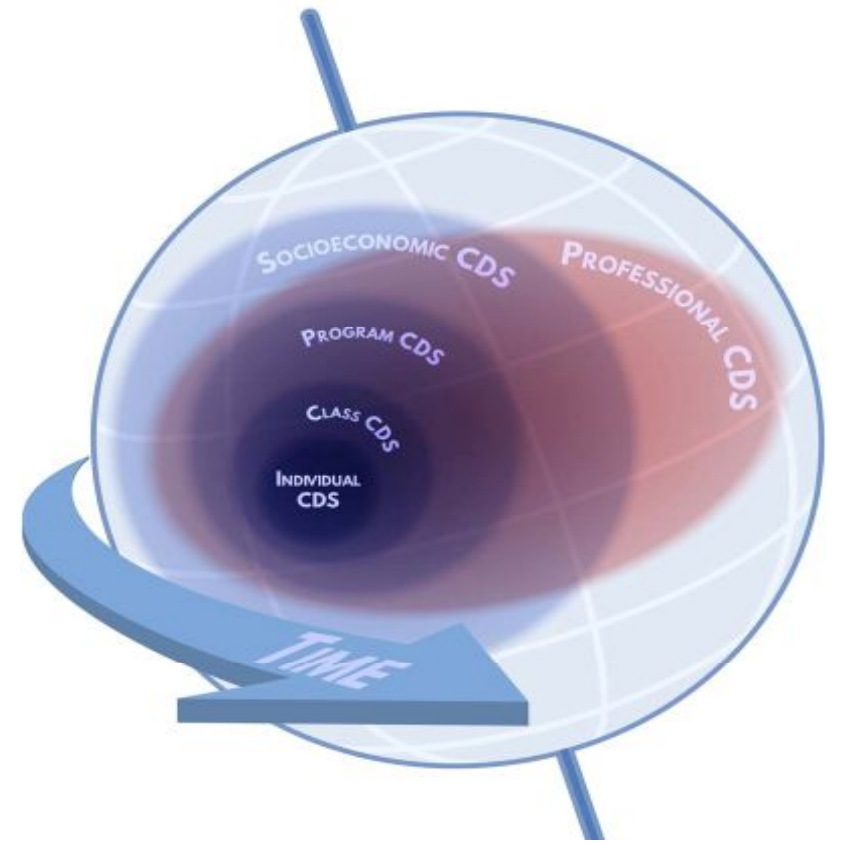

Figure 1: A CDS Model for ELT. CDS = complex dynamic system; ELT = English language teaching.

\section{The Socioeconomic Complex Dynamic System}

The model first places ELT within a Socioeconomic CDS, the very broad context in which English language programs, professionals, and learners exist. Given English's current global reach, ELT takes place in almost every country in the world. Each country has a unique Socioeconomic CDS created by the ongoing interaction of the country's economy, political system, history, geography, religion, society, technology, language, and culture. This system influences how English is perceived, why and how it is used, and when and how it is taught. In the past, when ELT was described, the Socioeconomic CDSs were divided into English-speaking systems (which yielded the term "Teaching English as a Second Language") and non-English-speaking systems (which yielded the term "Teaching English as a Foreign Language"). Subsequent terms attempted to move beyond the colonialism, economic imperialism, and other biases inherent in these labels: "Teaching English to Speakers of Other 
Languages," "Teaching English as an Additional Language," "Teaching English as a Lingua Franca," and "Teaching English as an International Language." None of these terms, however, acknowledge the uniqueness of each Socioeconomic CDS in which ELT takes place. An alternative approach is to investigate, understand, and acknowledge the elements that interact in each specific Socioeconomic CDS to make it distinct, particularly with respect to ELT. Our need to function effectively within this broad Socioeconomic CDS forms the first layer of possible CPD needs that we have as ELT professionals.

\section{The Profession Complex Dynamic System}

The Profession CDS describes the ELT profession resulting from its foundational theory and practice, educational qualifications, professional development channels, professional standards, and professional organizations. It is set against the historical context of ELT that has witnessed varying degrees of influence from a range of organizations since its birth, from nongovernmental organizations, to governments, to educational institutions, to for-profit companies both large and small. Over the past century, ongoing shifts in content priorities, learner demographics, and perspectives, and the agendas of mainstream culture have exerted influence on both the theory and practice of ELT (Burnaby, 1998).

Theory and practice refer to the knowledge and skills that the profession deems necessary for success, acquired either through pre-service education or CPD. The ongoing tension between theory and practice creates significant dynamic complexity in the Profession CDS. Both current and evolutionary conceptualizations of theory and practice in the field intersect simultaneously with the other elements within this CDS and across other CDSs in the model. Early understandings of ELT focused on concrete sets of knowledge that teachers were to impart using specific methodologies. Later, the profession developed its identity as one rooted in linguistics, applied linguistics, and psychology. This was followed by the exploration and creation of language acquisition theories and classroom methodologies, leading to today's postmethods era that balances theory and practice through the implementation of teaching principles (Brown \& Lee, 2015).

In our model, we identify theory as what we need to know about language (pronunciation, vocabulary, grammar, discourse, reading, writing, listening, speaking, linguistics, applied linguistics), first and second language acquisition, language teaching (methodologies, activities, resources, language assessment), and teaching (classroom management, behaviour management, education technology, learning disabilities, mental health, trauma, social justice, social integration). For practice, we identify the skills we need, including teaching skills (the four language skills, the four language systems, culture, lesson planning, materials development, classroom management, language assessment), technology skills (Microsoft Word, PowerPoint, and 
Excel; audio/video applications; Internet searching; social media; hardware, such as laptop or desktop computer, SmartBoard, projector), soft skills (verbal and nonverbal communication, written communication, interpersonal and intercultural communication, negotiating, advocacy), administrative skills (time management, record-keeping, organization, decision-making), and professional skills (teamwork, collaboration, change management).

The second element in the Profession CDS, educational qualifications, developed in tandem with the evolution of ELT theory and practice to give traction to the professionalization of the field. Qualifications include undergraduate degrees, short certificates and diplomas, and postgraduate degrees. Within this element, there is ongoing debate about the merits of educational qualifications that are viewed as short-term skills development exercises versus those that attend to the long-term development of English language teachers over time.

The next element, professional development channels, provides multiple choices for pre-service and CPD: formal learning, non-formal learning, and informal learning. Formal learning is intentional and graded learning, structured around a hierarchical curriculum. It is offered by accredited institutions and results in a recognized credential. Non-formal learning is also intentional and organized in some way but does not result in a recognized credential. Informal learning is unintentional, unorganized, incidental, and random (OECD, n.d.).

Within these professional development channels, there are other pertinent questions to be answered, including what formal CPD do we need or have access to? (e.g., certificate, diploma, undergraduate degree, postgraduate degree); what non-formal CPD do we need or have access to? (e.g., attending or presenting at workshops, webinars, conferences; mentoring; peer coaching; conducting research); what informal CPD do we need or have access to? (e.g., interacting with colleagues, social media posting and reading, participating in social media chats, blogging, writing articles, participating in professional learning networks, reading journals and books); and how do we track our professional development? (e.g., professional portfolio, e-portfolio, micro-credentialing).

The next element in the Profession CDS, professional organizations, exerts varying degrees of influence on English language professionals and their professional development choices. This influence is mediated by the scope of the organization (international, national, provincial, local), its focus (academic, community-based, intercultural, adult education, K-12), the level of engagement a professional has within the organization (member, director, committee member, advocate), and the vibrancy of the organization (extent of professional development offerings, status in the professional community, political engagement). Closely aligned with professional organizations is the element of professional standards that includes professional certification, best practice frameworks, and teacher training program accreditation. 


\section{The Program Complex Dynamic System}

Within the Profession CDS, each ELT professional functions within a specific ELT program, termed the Program CDS in our model. The Program CDS is not just our classroom or the institution at which we work. The Program CDS is created by the intersection of elements, such as location, institution, program, curriculum, methodology, resources, professional role, and program delivery modality. Our day-to-day experiences within the mutually influencing intersectionality of these elements create a unique set of CPD needs (Kostoulas, 2018).

The location describes the region (province or state), the type of community (rural area, small town, city, large urban area) and the characteristics of the region and community that may impact our ELT. The institution describes the type of institution (publicly funded school board, private language school, community college, private career college, university, nonprofit organizations [e.g., settlement centres, multicultural centres, religious centres, and community centres], privately owned businesses), the institution funding (federal, provincial or state, local, private, learner fees), the institution management (organizational structure, stakeholders), and the ELT services offered (instruction, assessment, publishing or distributing, teacher education, other consulting services).

The program element generally describes the types of learners we teach (international learners, international professional groups, visitors, immigrants, temporary foreign workers, refugees, residents, citizens), the age of our learners (pre-primary, elementary school, high school, college, university, working adults, seniors), their language proficiency levels (literacy, beginner, intermediate, advanced), the language proficiency framework used (Canadian Language Benchmarks, Common European Framework of Reference, Global Scale of English, in-house proprietary language proficiency framework), and the courses or programs we teach (Literacy and Basic Skills, General English, Conversation Circles, Citizenship, English for Academic Purposes, Workplace English, Professional English, Occupation Specific Language [e.g., health care, aviation, oil and gas, finance, and Information Technology or IT], Business English, Academic Bridging, English for Special or Specific Purposes [e.g., parenting, camping, the arts, public speaking, and computer literacy]). Along with each program, there are corresponding curricula, methodologies, and resources.

Another element within the Program CDS is the professional role. This describes the different roles in the organization and the responsibilities associated with each role (teacher, assessor, curriculum developer, materials developer or author, teacher trainer, program reviewer and accreditation auditor, counsellor, employment counsellor, learner advocate, recruiter, manager or administrator, marketing manager, entrepreneur, owner) and the level of experience in the role (pre-service, novice, experienced, expert). 
Finally, program delivery modality refers to how we deliver the English language instruction (face-to-face in a classroom or shared space, such as a workplace, library, cafe, or childcare centre; blended face-to-face and online; synchronous online video conferencing; synchronous or asynchronous telephone or online audio; virtual reality).

All elements of the Program CDS require that English language teachers have different knowledge and skills. As they move around in the Program CDS and from one Program CDS to another, the requirements for knowledge and skills change. The requirements also change over time as each Program CDS changes.

\section{The Class Complex Dynamic System}

Within a Program CDS, there are multiple Class CDSs in which teaching and learning occur, for the language classroom is also a CDS (Tudor, 2001; Dörnyei, 2014; Kostoulas, 2018). The Class CDS is not just a physical space; it refers very broadly to the learners who are gathered together in a particular physical or virtual space for the purpose of learning English. Most teaching still occurs in traditional classroom spaces, but there are also community locations and rapidly increasing online platforms that are also classrooms. The elements in the Class CDS include class size, individual language levels, learner demographics, learner life experience, and learner motivation.

Class size refers to the number of learners interacting with the teacher. This can vary from a single learner with a tutor, to online asynchronous teaching to hundreds of learners. The number of learners defines the number of interrelationships that occur among learners, peers, and teachers. Learners themselves can be considered CDSs (Mercer, 2011b, 2016); a class is, thus, a group of learner CDSs that program administrators attempt to group together based on defined commonalities. This group of learner CDSs is a significant contributor to the complexity and unpredictability of the Classroom CDS.

Whereas language level comes into play in a broad sense in the Program $\mathrm{CDS}$, the individual language levels of each learner, as well as the degree of variance in the language levels, are elements that act in the Class CDS. Similarly, learner demographics are an element in the Class CDS as the characteristics of the individual learners in a class interact. This includes characteristics such as race, ethnicity, gender, age, education, profession, occupation, income level, and marital status. The element we have termed learner life experience encompasses a wide array of cultural, social, economic, and psychological factors, including pre- and post-migration experiences, family relationships, cultural connectedness, trauma, and post-traumatic stress. Another important element in the Class CDS is learner motivation. What motivates the learner to learn English, and what end goal do they want to reach? These goals vary immensely from wanting to learn basic practical language for conducting daily life to passing high-stakes examinations. 
The complexity of the Class CDS becomes obvious when we start to consider the myriad combinations of language level, demographics, life experiences, and motivations that can occur in one single class. These permutations, combined with the elements in the other intersecting CDSs, impact what optimal teaching would look like, and consequently what professional development choices a conscientious teacher might make.

\section{The Individual Complex Dynamic System}

Given that individuals can be considered CDSs (Mercer, 2011a), the final CDS in our model is the individual ELT professional. For the purposes of our model, the Individual CDS - the ELT professional - is comprised of three main elements: the extent and nature of the teacher's education and training, the extent and nature of the teacher's professional experience, and the self. All three elements are exhibited in the specific role that the teacher has in the program.

A teacher's level of education and training determines the starting point for next steps in professional development. In Canada, for example, there is variation in the education backgrounds of ELT professionals. An increasing number of professionals hold specific ELT degrees, but many hold university degrees in related fields, such as K-12 education, adult education, psychology, and sociology; in some cases, ELT professionals have degrees entirely unrelated to teaching. Similarly, many teacher training programs exist, some that offer lengthy, detailed training and others that are introductory. Finally, because the professionalization of the field is a relatively new phenomenon, and because there are communities where the need for English language classes has preempted the capacity of the community to access qualified professionals, there are many ELT professionals with little to no formal training working in many programs and classrooms. Therefore, it is important for individual professionals to assess their own education and training when determining their CPD needs. It is also important for those delivering CPD opportunities to consider the individual differences that may exist within their schools or programs.

The same dynamism emerges when we consider professional experience. Length, breadth, and depth of experience are factors that impact an individual's overall level of experience. Certainly, professional experience yields many transferable skills that allow individuals to migrate across programs. However, there are significant differences in what is required to teach, for example, in an English for academic purposes class in a university setting compared with a community-based English program held in a settlement agency. Years of experience in one sphere will only minimally prepare us for work in the other, and, thus, professional development needs may shift with a change in employment. 
The final element in the Individual CDS, self, includes multiple individual qualities, such as personality traits, personality type, learning preferences, motivations, critical thinking skills, personal autonomy, and assumptions. These all interact to define a unique individual teacher with distinct CPD needs and tendencies. It is beyond the scope of this article to comprehensively explore the element of self and how this impacts an educator's professional development trajectory. A thorough exploration of this topic can be found in Patricia Cranton's book Professional Development as Transformative Learning: New Perspectives for Teachers of Adults (1996). In the text, she explores educators' professional development using several theoretical frameworks: Jungian psychological type theory (Jung \& Hull, 1971), Brookfield's (1987) critical thinking theory, Candy's (1991) theory of self-direction, and Mezirow's (1991) theory of transformative learning (Cranton, 1996; Marrocco, 2009).

In a subsequent work, Cranton (2006) advocates taking the time to muse about ourselves as educators and lists a series of reflective questions to prompt this: How would I describe my learning and teaching style? What is my philosophy of practice? What do I like and dislike about being an educator? What do my learners think an educator should be like? What inhibitions or fears do I have about my work? Questions such as these serve as a valuable guide to selecting a CPD pathway. Taking a fresh look at transformative learning theory using a lens that places the ELT professional as the learner reveals the significance of the individual difference in professional development and the symbiotic relationship between the individual and the Socioeconomic CDS.

\section{Implications of the Complex Dynamic Systems Model for Continuing Professional Development}

The CDS model of the ELT profession has multiple implications for CPD. First, because CDSs are complex, non-linear, and unpredictable, the CPD for teachers also needs to be complex, non-linear, and-yes-even unpredictable. There is no one single, simple, magic wand for CPD that will miraculously address all learning needs. Instead, CPD needs to be multi-faceted and multi-channelled, approaching issues and needs from different angles and perspectives.

The complexity of CPD is evident in the sheer scope of knowledge and skills to be learned by English language teachers that a CDS lens uncovers, with new knowledge and skills added every day. In our work, we often encounter experienced teachers who tell us, "I have been teaching English for twenty-five years. There is nothing that I need to learn." The CDS model shows how misguided this perception is. Instead of this limited view of the profession and what needs to be learned, the CDS model uncovers a plethora of CPD needs and opportunities across all CDSs in the socioeconomic, 
profession, program, class, and individual realms. Beyond that, there are needs and opportunities where the Profession CDS extends globally, yielding needs and opportunities locally, regionally, nationally, and globally. It also yields opportunities formally, informally, and non-formally, through multiple channels. CPD has never been so needed, and its opportunities more numerous or accessible.

Second, because of the dynamic nature of all the CDSs that intersect in ELT, the CDS model highlights the need for continuing professional development, not just professional development. Our choice of the term CPD rather than PD is intentional. As conscientious professionals, we must regularly evaluate the relevancy and currency of our knowledge and skills by scanning all of the CDSs. We need to be self-aware and identify gaps that have emerged in our knowledge and skills based on the changes we see. Keeping in mind that we are ourselves a CDS, we also need to be aware of how we have changed over time, for better or for worse. A CDS lens focuses our attention on change; with this lens, we see that our CPD is never complete, nor is it predetermined. We need to be both open to new learning, and flexible and agile as to what that new learning might be.

Third, the model allows us to understand what makes our ELT context particularly unique and identify the specific knowledge and skills that we need to be effective and successful in this unique context. Given the infinite knowledge and skill possibilities that exist for our CPD, using this contextual information to strategically select how we spend our CPD time and money makes our decision-making more efficient and our CPD more relevant.

Fourth, the CDS model refutes another misguided perception: that there is only one right way to teach English. If there are thousands of teachers, in thousands of classes, in thousands of programs, in thousands of socioeconomic contexts, all intersecting uniquely and changing over time, then suffice it to say that there is more than one "right" way to teach English. To fully appreciate the richness, complexity, and impact of ELT, we need to see our profession through a lens that is not confined to our individual ELT contexts. We need to get beyond the judgemental position of "I believe this about my profession and everyone should believe as I do" to an understanding that what we believe as individual ELT professionals is based upon our experiences in the contexts in which we teach. This then allows for the beliefs of other ELT professionals, derived from other contextual experiences, to be validated. Rather than pursuing CPD to learn the one "right" way to teach English, we should build up our repertoire of approaches, methods, techniques, and activities, so that we can strategically select the most effective and efficient way to teach at a specific point in time with a specific group of learners. The larger the repertoire, the greater the likelihood of success.

To further expand on this implication, within ELT, there are many different kinds of teaching resulting from the intersectionality of the different CDSs in our contexts. Rather than taking a myopic, insular perspective on ELT, 
thinking there is only one way to teach English, and thus limiting our professional development and our career options, we need to take a larger, more inclusive view of the profession. Taking a myopic perspective diminishes the profession and our roles as ELT professionals within it. Understanding that there are multiple ways to teach expands the importance of the profession and makes the impact that the profession has as an agent of change in a society very clear.

The final implication of the model initially appears to be a contradiction. On one hand, the situated, context-specific nature of the ELT profession suggests that we should aspire to a very narrow CPD focus customized to a unique context. On the other hand, the richness of the interrelated factors, ongoing change, and subsequent learning opportunities in the intersecting, nested CDSs with which we interact suggests that we should aspire to wideranging CPD that connects us to the knowledge and practice of the entire constellation of the ELT profession. The resolution to this contradiction is not "either/or" but "all." We must strategically balance our need to build our expertise for teaching in a particular context with our need to simultaneously interact with and learn from all of the knowledge growth and change in practice taking place in all of the CDSs to which we are integrally linked.

\section{Conclusion: A Unique Continuing Professional Development Pathway}

To fully appreciate our profession, and the career opportunities and rewards within it, we must engage with its complexity rather than cling to a narrow and simplified understanding of it based upon the single limited ELT context in which we work. Reflecting on the CDSs in our proposed model of the ELT profession and their corresponding intersectionality will support effective decisions with respect to the personal CPD pathways that each of us, as ELT professionals, strategically construct for ourselves. Understanding the uniqueness of our teaching realities, as well as the interconnectedness and interplay among the CDSs of which we are a part, allows us to engage in intentional and strategic CPD that is itself complex and dynamic. All stakeholders in the ELT profession can use the CDS model applied to CPD to identify, support, and build an impactful vision for their future and the future of the profession.

\section{The Authors}

Dianne Tyers has 30 years of experience in English language education as a teacher, teacher educator, manager, program developer, program evaluator, and researcher. She has a PhD from the Ontario Institute for Studies in Education (OISE), University of Toronto, as well as a Master of Arts in Applied Linguistics from the University of Queensland. She currently runs Advance Consulting for Education, providing teacher education and consulting services across Canada and internationally. 
Judy Sillito holds a Master of Education degree from the University of Alberta. For 38 years, she has worked in English language education in a variety of capacities_teacher, program developer, manager-in programs ranging from Language Instruction for Newcomers to Canada to English for the Workplace to English for Academic Purposes to arts-based and literacy-focused community based-learning initiatives. She is employed at Multicultural Health Brokers Cooperative in Edmonton, $\mathrm{AB}$, where she designed and now manages an English for Employment program for immigrants and refugees facing multiple barriers to employment.

\section{References}

Brookfield, S. (1987). Developing critical thinkers: Challenging adults to explore alternative ways of thinking and acting. San Francisco, CA: Jossey-Bass.

Brown, H. D., \& Lee, H. (2015). Teaching by principles: An interactive approach to language pedagogy (4th ed.). White Plains, NY: Pearson Education.

Burnaby, B. (1998). English as a second language for adult immigrants. In S. Scott, B. Spencer, \& A. Thomas (Eds.), Learning for life: Canadian readings in adult education (pp. 283-295). Toronto, ON: Thompson Educational Publishing.

Candy, P. (1991). Self-direction for lifelong learning: A comprehensive guide to theory and practice. San Francisco, CA: Jossey-Bass.

Cranton, P. (1996). Professional development as transformative learning: New perspectives for teachers of adults. San Francisco, CA: Jossey-Bass.

Cranton, P. (2006). Understanding and promoting transformative learning: A guide for educators of adults (2nd ed.). San Francisco, CA: Jossey-Bass.

De Bot, K., Lowie, W., \& Verspoor, M. (2007). A dynamic systems theory approach to second language acquisition. Bilingualism: Language and Cognition, 10(1), 7-21. DOI:10.1017/ S1366728906002732

Dörnyei, Z. (2014). Researching complex dynamic systems: "Retrodictive qualitative modelling" in the language classroom. Language Teaching, 47(1), 80-91. DOI:10.1017/S0261444811000516

Hensley, J. (2010). A brief introduction and overview of complex systems in applied linguistics. Journal of the Faculty of Global Communication, 1, 83-95. http://hdl.handle.net/10561/678

Jung, C., \& Hull, R. (1971). Psychological types (Vol. 6). Princeton, NJ: Princeton University Press.

Kostoulas, A. I. (2018). A language school as a complex system: Complex systems theory in English language teaching. Bern, Switzerland: Peter Lang Publishing Group. DOI:10.3726/b11892

Kostoulas, A. I., Stelma, J., Mercer, S., Cameron, L., \& Dawson, S. (2017). Complex systems theory as a shared discourse space for TESOL. TESOL journal, 9(2), 246-240. DOI:10.1002/tesj.317

Larsen-Freeman, D. (1997). Chaos/complexity science and second language acquisition. Applied Linguistics, 18(2), 141-165. DOI:10.1093/applin/18.2.141

Larsen-Freeman, D., \& Cameron, L. (2008). Complex systems and applied linguistics. Oxford, UK: Oxford University Press.

Marrocco, M. J. (2009). Understanding and promoting transformative learning: A guide for educators of adults. Canadian Journal of University Continuing Education, 35(1), 67-69. DOI:10.21225/D5Z59X

Mercer, S. (2011a). The self as a complex dynamic system. Studies in Second Language Teaching and Learning, 1(1), 57-82. DOI:10.14746/ssllt.2011.1.1.4

Mercer, S. (2011b). Understanding learner agency as a complex dynamic system. System, 39(4), 427-436. DOI:10.1016/j.system.2011.08.001

Mercer, S. (2016). Complexity and language teaching. In G. Hall (Ed.), The Routledge handbook of English language teaching (pp. 473-485). Abingdon, UK: Routledge.

Mezirow, J. (1991). Transformative dimensions of adult learning. San Francisco, CA: Jossey-Bass.

Organisation for Economic Co-operation and Development/Organisation de Coopération et de Développement Economiques (OECD). n.d. Retrieved from http://www.oecd.org/education/ skills-beyond-school/recognitionofnon- formalandinformallearning-home.htm 
Stelma, J., Fay, R., \& Zhou, X. (2013). Developing intentionality and researching multilingually: An ecological and methodological perspective. International Journal of Applied Linguistics, 23(3), 300-350. DOI:10.1111/ijal.12040

Tudor, I. (2001). The dynamics of the language classroom. Cambridge, UK: Cambridge University Press.

Van Geert, P. (2008). The dynamic systems approach in the study of L1 and L2 acquisition: An introduction. The Modern Language Journal, 92(2), 179-199. DOI:10.1111/ j.1540-4781.2008.00713.x

Verspoor, M. H., de Bot, K., \& Lowie, W. (2011). A dynamic approach to second language development: Methods and techniques. Amsterdam, Netherlands: John Benjamins Publishing Co.

Young, M. F., DePalma, A. \& Garrett, S. (2002). Situations, interaction, process and affordances: An ecological psychology perspective. Instructional Science, 30(1), 47-63. DOI: 10.1023/A:1013537432164 